\title{
Correction to: Kin bias and male pair-bond status shape male-male relationships in a multilevel primate society
}

\author{
Federica Dal Pesco ${ }^{1,2,3}$ (D) Franziska Trede ${ }^{1,3}$ (D) Dietmar Zinner $^{1}$ (D) $\cdot$ Julia Fischer ${ }^{1,2,3}$ (I)
}

Published online: 19 February 2021

(C) Springer-Verlag GmbH Germany, part of Springer Nature 2021

\section{Correction to: Behavioral Ecology and Sociobiology. https://doi.org/10.1007/s00265-020-02960-8}

Due to a mistake during the proofing process the range values were erroneously removed from the sentence "Remarkably, $66.7 \%$ of bachelor males (10 of 15 males) were associated with multiple primary males (average number of units 2.53 $\pm 1.36 \mathrm{SD}$; median $=3.00$ )" on page 8 .

This sentence should instead read "Remarkably, $66.7 \%$ of bachelor males ( 10 of 15 males) were associated with multiple primary males (average number of units $2.53 \pm 1.36 \mathrm{SD}$; range $=1$ to 5 ; median $=3.00$ )".

Publisher's note Springer Nature remains neutral with regard to jurisdictional claims in published maps and institutional affiliations.

The online version of the original article can be found at https://doi.org/ 10.1007/s00265-020-02960-8

Federica Dal Pesco

fdalpesco@dpz.eu

1 Cognitive Ethology Laboratory, German Primate Center, Göttingen, Germany

2 Leibniz ScienceCampus Primate Cognition, Göttingen, Germany

3 Department for Primate Cognition, Georg-August-University Göttingen, Göttingen, Germany 